•研究报告・

\title{
如何在北京充分实现受胁鸟类栖息地保护?
}

\author{
黄越 ${ }^{1 \# \text {, 顾炎炎芸 }{ }^{2 \#} \text {, 阳文锐 }{ }^{3}, \text { 闻丞 }}{ }^{2,4,5 *}$
}

1. 中国农业大学园艺学院, 北京 100094; 2. 北京镜朗生态科技有限公司, 北京 100091; 3. 北京市城市规划设计研究院, 北京 100045;

4. 昆明市朱雀鸟类研究所, 昆明 650233; 5. 北京大学生命科学学院, 北京 100871

摘要: 实现有效生物多样性保护的关键在于提升生物多样性丰富的人口密集区的保护效率。北京人口密集且生物多样性丰 富, 存在3类具有生态保护功能的区划——自然保护区、生态保护红线和限制建设线。上述区域可视为生态保护潜力区。本 文以在北京有分布的 30 种受胁鸟类为主要对象，探讨现有生态保护潜力区对这些物种栖息地的覆盖程度, 并对如何改善上述 受胁鸟类栖息地的保护状况进行了建议。根据物种对栖息地的选择，基于高分辨率卫星解译的土地利用类型图，利用最大熵 模型(MaxEnt)掩膜栖息地分布图, 得到各受胁鸟类的预测空间分布。叠加这些分布获得北京受胁鸟类丰富度分布格局并进行 验证。依据物种丰富度高低, 将受胁鸟类栖息地划分为一至四级(最重要的栖息地是一级栖息地，以此类推)。同时，依据地表 覆盖类型和人类活动强度高低将北京市域划分为城市建成区、乡村生境区和自然生境区。分别计算3类保护潜力区对上述3 类区域以及四级栖息地的覆盖面积比例。结果表明: (1) 95.64\%的一级关键栖息地和 $86.32 \%$ 的二级关键栖息地分布在乡村生 境区，但仅有 $0.69 \%$ 和 $15.15 \%$ 的乡村生境区分别被自然保护区和生态保护红线覆盖; (2)未受到自然保护区和生态保护红线覆 盖的一、二级关键栖息地主要为水域和沼泽地等湿地、高覆盖度草地和部分耕地, 以及含有较高比例水体的大型城市绿地。 基于以上结果, 我们建议至少在一定区域内试行如下保护措施: (1)严格保护湿地及其周边的高覆盖度草地, 确保面积不减少; (2)维持基本农田规模和粮食种植模式; (3)将乡村生境区位于河道附近的水域、沼泽地、高覆盖草地和灌木林纳入生态保护红 线范围; (4)在公园绿地中划定生物多样性保护区; (5)优化平原地区林地结构。以上措施将使北京的受胁鸟类栖息地得到更好 保护, 为中国东部人口密集区生物多样性保护提供示范。

关键词: 受胁鸟类栖息地; 生物多样性保护; 保护潜力区; 乡村生境区; 湿地; 城市绿地; 北京

黄越，顾炏芸，阳文锐，闻丞 (2021) 如何在北京充分实现受胁鸟类栖息地保护? 生物多样性, 29, 340-350. doi: 10.17520/biods.2020171.

Huang Y, Gu YY, Yang WR, Wen C (2021) How to best preserve the irreplaceable habitats of threatened birds in Beijing? Biodiversity Science, 29, 340-350. doi: 10.17520/biods.2020171.

\section{How to best preserve the irreplaceable habitats of threatened birds in Beijing?}

Yue Huang ${ }^{1 \#}$, Yiyun $\mathrm{Gu}^{2 \#}$, Wenrui Yang ${ }^{3}$, Cheng Wen ${ }^{2,4,5^{*}}$

1 College of Horticulture, China Agricultural University, Beijing 100094

2 Beijing Jinglang Ecological Technology Ltd., Beijing 100091

3 Beijing Municipal Institute of City Planning and Design, Beijing 100045

4 Kunming Rosefinch Bird Research Institute, Kunming 650233

5 School of Life Sciences, Peking University, Beijing 100871

\section{ABSTRACT}

Aims: Protecting biodiversity in highly populated metropolises is an important effort for global biodiversity conservation. Beijing is home not only to a large human population, but also large biodiversity clusters. Three levels of conservation management have been administratively delimited: the nature reserves, the ecological red line, and the construction control line. These groups, as a whole, represent the potential areas for conservation (PAC). We intend to

收稿日期: 2020-04-26; 接受日期: 2020-09-06

基金项目: 国家重点研发计划课题(2016YFC0503301); 基于生物多样性的区域生态网络构建研究

\# 共同第一作者 Co-first authors

* 通讯作者 Author for correspondence. E-mail: 82335884@qq.com 
explore the methods to conserve the endangered species of birds in Beijing.

Methods: Here, we explored the coverage of 30 recently recorded threatened bird species based on the existing PAC. Based on each selected species' habitat preferences, we calculated the species distribution models and combined it with the land use and land cover map to generate the potential distribution map. We then overlayed those maps to obtain the overall distribution pattern in Beijing for the selected bird species. This distribution pattern enabled us to calculate the species richness at any interested sites within our study area.

Results: Based on the species richness map, we ranked all habitats as four grades based on the number of endangered species present. We also classified urban, rural, and natural areas based on the intensity of urban land use and human activities. This allowed us to calculate the coverage of our ranked key habitats and different urbanization gradient by each of the three PAC groups. We had two major findings. First, $95.64 \%$ of grade I and $86.32 \%$ of grade II habitats are within the rural areas, whereas merely $0.69 \%$ of the rural areas are covered by nature reserves and $15.15 \%$ by the ecological protection red line. Second, the defined key habitats ranked as grade I and II but not yet under the umbrella of either the nature reserves or the ecological protection red line are mainly wetlands (waterbodies and marshlands), high coverage grasslands, farmlands, and some large-scale green patches in urban areas with large bodies of water. Based on these results, we offer the following suggestions to help with conservation: (1) preservation of wetlands and the high coverage grasslands surrounding the urban cores efficiently; (2) maintaining the scale of basic farmland and food crop planted; (3) including all bodies of water, marshlands, and high coverage grasslands alongside rivers in ecological protection red line area; (4) delimiting biodiversity conservation zones in large urban greenspaces such as major urban parks; and (5) optimizing the structure of woodland communities in rural and urban areas to satisfy the habitat needs of some specialist species.

Conclusion: Implementing those conservation practices will provide Beijing with more diverse avian communities. These efforts could be a good case for biodiversity conservation in other major cities of China to follow.

Key words: habitats of threatened birds; biodiversity conservation; potential areas for conservation; rural habitat; wetland; urban green spaces; metropolitan Beijing

2010年, 《生物多样性公约》第十次缔约方大 会通过了生物多样性“爱知目标”。“爱知目标”的主 要内容之一是至2020年, 生物多样性保护区应覆盖 全球17\%的陆地面积(CBD, 2011)。尽管中国保护地 面积截至2017年已达到国土面积的约18\%（唐小平 和奕晓峰, 2017), 但放眼中国东部地区, 农田、城镇 广布, 保护地覆盖不足, 而该区域恰恰又是包括鸟 类在内的最受关注濒危物种的重要分布区域(闻丞 等, 2015; Hu et al, 2017)。类似情况也见于全球其他 生物多样性较丰富的国家(Mittermeier et al, 1999)。

北京是中国的首都, 城市化率高达86.5\% (北 京市统计局和国家统计局北京调查总队, 2019), 是 全世界人口最稠密、经济最发达的地区之一。同时, 北京所处的华北地区也是全球自然环境受损最严 重的区域之一, 超过 $80 \%$ 土地上的自然生态系统已 经被人为改变(Dinerstein et al, 2017)。对北京生物多 样性保护策略的分析结果对中国其他人口密集区 具有示范意义。

自然保护区是针对有代表性的保护对象所在 的区域依法划出一定面积予以特殊保护和管理的
区域, 是对包括生物多样性在内自然资源的重要保 护形式。自20世纪80年代以来, 北京建立了 17 个自 然保护区。2006年, 北京市批准《北京市限建区规 划(2006年-2020年)》作为北京城市总体规划(2004 年-2020年)的专项规划之一, 从限制建设的角度将 北京市域74.4\%的土地划入限制建设线(禁建或限建) (龙瀛等, 2006; 何永, 2008; 丁志刚, 2009)。生态保 护红线是生态空间范围内具有特殊重要生态功能、 必须强制性严格保护的区域(郑华和欧阳志云, 2014)。2018年，北京市人民政府发布北京市生态保 护红线(http://www.beijing.gov.cn /zhengce/zhengcefa gui/201905/t20190522_61382.html), 面积占市域国 土面积的 $26.1 \%$ 。上述自然保护区、限制建设线和 生态保护红线均以生态保护为目的, 对存在于其间 的生物多样性起到保护作用, 故可被称为 “生态保 护潜力区” (下文简称“保护潜力区”)。

鸟类是具有高度移动性的环境指示物种, 能够 迅速地反映环境现状及其变化 (Herrando et al, 2012)。北京现有的“保护潜力区”对受胁鸟类栖息地 的保护效果如何? 为解答上述问题, 本研究尝试: 
(1)以在北京有分布的受胁鸟类作为指标物种, 界定 北京市域的受胁鸟类栖息地并对其进行分级; (2)分 别分析 3 类保护潜力区对北京市域各级受胁鸟类栖 息地的覆盖情况; (3)依据所处区域的栖息地重要性 级别、类型及其被保护潜力区覆盖的情况, 分别探 讨各类受胁鸟类栖息地的适宜保护和管理措施。

\section{研究方法}

\section{1 研究区域及分区}

本文以北京市域为研究范围 (图1), 总面积 $16,405 \mathrm{~km}^{2}$ 。北京位于华北平原西北端, 西侧和北侧 分别是太行山和燕山, 整体地势西北高, 东南低。 自然植被以暖温带落叶阔叶林和针阔混交林为主。

目前，北京城市建成区完全位于华北平原和延 庆平原，地表覆盖以不透水表面为主。农田、河流、 村庄、水库、大型绿地斑块等用地类型集中在北京 主城区周边海拔 $300 \mathrm{~m}$ 以下的浅山区以及延庆平原 周边海拔 $600 \mathrm{~m}$ 以下的浅山区(人工用地总计占 49.44\%), 本文将此类区域视为乡村生境区。北京市 平原地区周边海拔 $300 \mathrm{~m}$ 以上山区及延庆平原周边 海拔600 m以上山区地表主要被次生林和灌从覆盖, 人为干扰较少 (人工用地仅占 $1.54 \%$ ), 本文将此类 区域视为自然生境区(图1)。

\section{2 数据来源}

\subsection{1 卫星影像图和数字高程模型}

获取来自谷歌地球(Google Earth)的高分卫星 影像, 空间分辨率为 $0.5 \mathrm{~m}$, 覆盖北京市城市建成区 和乡村生境区范围, 时相以2017年夏季为主。自然 生境区卫星影像图下载自中科图新——图新地球4 互联网免费三维数字地球, 分辨率为 $5 \mathrm{~m}$; 同时获 取该区域精度为 $30 \mathrm{~m}$ 的数字高程模型。

\subsection{2 北京市域受胁鸟类及其栖息地类型}

基于IUCN的最新评估报告，北京市域范围内 分布有30种受胁鸟类(IUCN，2020; Lepage，2021), 名录如附录 1 。其中, 褐头鸫(Turdus feae)繁殖季节 主要分布在自然生境区, 迁徙季节在城市绿地有零 星记录; 褐马鸡(Crossoptilon mantchuricum)全年生 活在自然生境区; 其余受胁鸟类均为迁徙过境或冬 候鸟, 偏好平原区和浅山区的乡村生境, 或大面积 城市绿地。依据《中国动物志・鸟纲》(中国科学院
中国动物志编辑委员会, 1978-2010)和《中国鸟类野 外手册》(MacKinnon et al, 2000)等文献，参考北京 市域各区的土地利用特征和“中国土地资源分类系 统” (http://www.resdc.cn/data.aspx?DATAID=99)，归 纳出北京市共分布有 5 个一类、 18 个二类鸟类栖息 地(附录1)。

\subsection{3 鸟类分布数据}

从中国观鸟记录中心数据库获取在北京市域 分布的 30 种受胁鸟类的点位数据(http://www.birdre port.cn/index.html), 并在 Google 地图中对其坐标进 行人工校正。数据时限主要为 2002-2013 年, 并补 充了 2014-2015 年部分鸟种数据。中国观鸟记录中 心数据库鸟类分布点位经专家人工审核，基于该数 据库数据已发表多篇文章(Hu et al, 2017; Li et al, 2020)。协议获取 eBird 数据库 26 种受胁鸟类点位 空间坐标作为模型验证数据, 时限为 2013-2020 年 (eBird Basic Dataset, 2020)，未收录黑脸琵鹭 (Platalea minor)、玉带海雕(Haliaeetus leucoryphus)、 黄嘴白鹭(Egretta eulophotes)和白喉林能 (Cyornis brunneatus)记录点。此外还参考了在北京猛禽监测 点(Wen \& Han, 2013)和城市绿地(Huang et al, 2015) 开展的鸟类调研监测工作。

\subsection{4 保护潜力区范围}

从北京市城市规划设计研究院协议获取北京 市自然保护区、北京市生态保护红线和北京市限制 建设线 3 类保护潜力区数据。

\section{3 数据分析}

\subsection{1 受胁鸟类栖息地空间分布}

在地理信息系统(ArcGIS)中，使用镶嵌工具拼 接建成区和乡村生境区以及自然生境区卫星影像。

在城市建成区和乡村生境区采用土地利用及 斑块面积等为主要因子提取除褐头冻和褐马鸡以 外的受胁鸟类栖息地。按照上文 1.2.2 节所述鸟类 栖息地分类体系，在卫星影像图上对北京城市建成 区和乡村生境区的鸟类栖息地进行目视解译，获得 各区域鸟类栖息地分布图。

在自然生境区采用海拔、坡向、植被类型等作 为主要因子提取褐头鸫和褐马鸡的栖息地。褐头冻 主要分布在海拔 $1,000 \mathrm{~m}$ 以上的成熟林地 (MacKinnon et al, 2000), 尤其是海拔1,730-1,930 m 
的华北落叶松(Larix principis-rupprechtii)林。褐马鸡 在北京分布于海拔950-2,200 m, 坡向从东南135至 西北335 (张国钢等, 2004; 宋凯等, 2016)的针叶 林、针阔混交林、灌从林和草地的组合生境(张国钢
等，2003，2005，2010)。依据以上栖息地选择特征， 提取褐头冻和褐马鸡栖息地。

融合城市建成区、乡村生境区和自然生境区栖息 地，获得北京市域受胁鸟类栖息地空间分布图(图 2)。

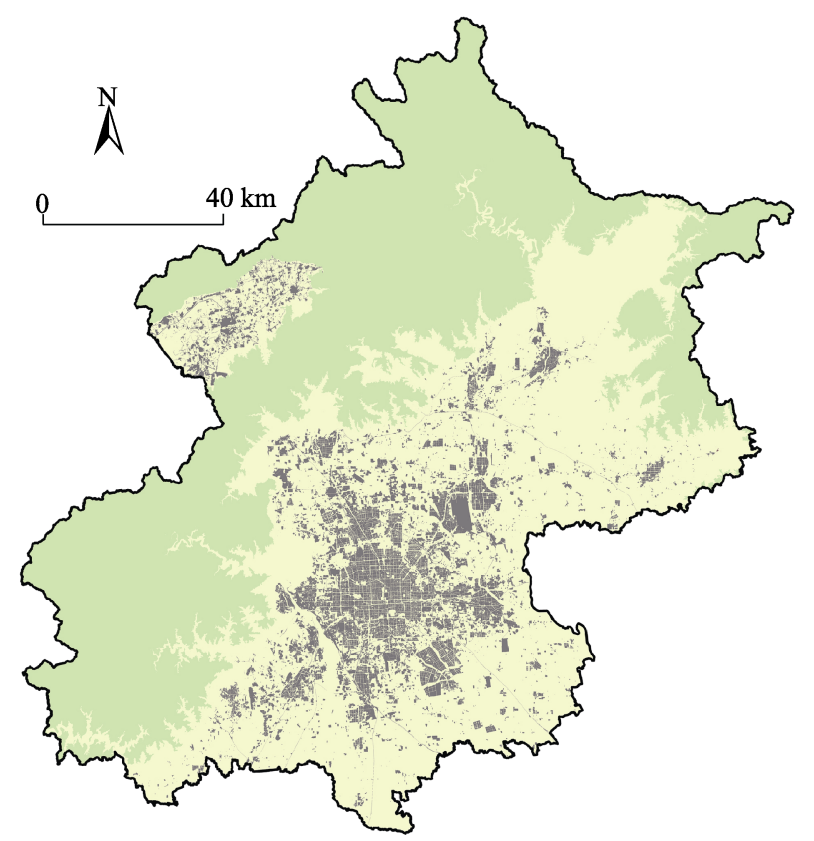
图例 Legend
北京市域边界 Boundary of Beijing
城市建成区 Urban area
乡村生境区 Rural area
自然生境区 Natural area

图1 北京市域城市建成区、乡村生境区和自然生境区范围

Fig. 1 The range of urban area, rural area and natural area in Beijing

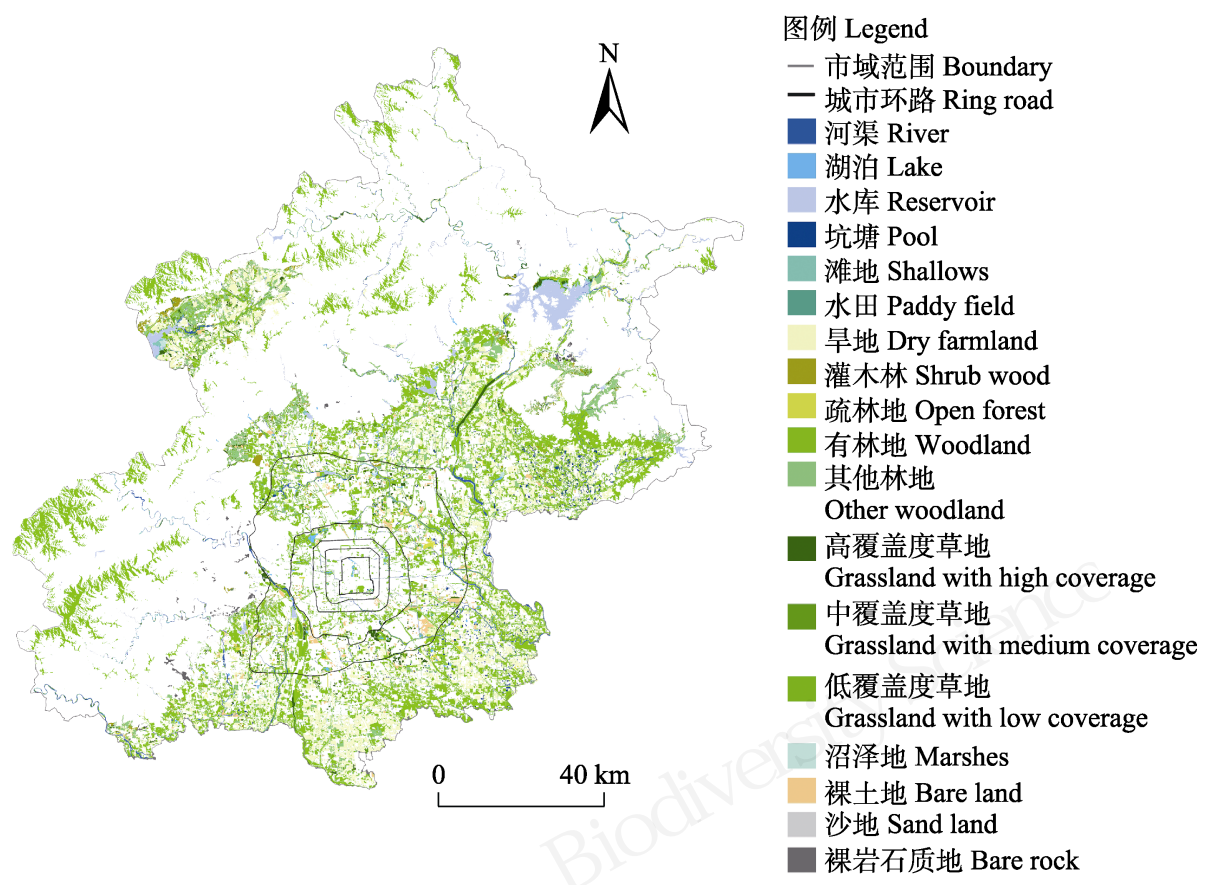

图2 北京市域受胁鸟类栖息地空间分布(其位于城市建成区、乡村生境区和自然生境区的比例分别是 $4.49 \% 、 81.14 \%$ 和 $14.37 \%$ ) Fig. 2 The distribution map of the habitats of threatened birds in Beijing. The coverage ratio of the habitats of threatened birds to urban, rural and natural areas was $4.49 \%, 81.14 \%$, and $14.37 \%$, respectively. 


\subsection{2 受胁鸟类丰富度分布格局、栖息地分级及验证}

使用30种受胁鸟类的实际空间分布点位, 采用 最大熵模型(MaxEnt)得到各鸟种全国尺度空间分布， 并生成二值化栅格图层，精度为1 km (闻丞等, 2015; Hu et al, 2017)。根据1.3.1节获得的鸟类栖息地分布 以及每种受胁鸟类的栖息地选择进行掩膜处理, 掩 膜精度为 $30 \mathrm{~m}$, 获得每种受胁鸟类预测分布图层。 将30种受胁鸟类预测分布图层在ArcGIS软件中直 接叠加, 得到北京市域受胁鸟类丰富度分布格局。

根据受胁鸟类丰富度分布格局栅格数值, 将得 分为 10 以上的栅格划分为一级关键栖息地; 得分 5-10的划分为二级关键栖息地; 得分 3-5的划分为 三级栖息地; 得分 $1-3$ 的为四级栖息地。

将从 $\mathrm{eBird}$ 获取的 26 种受胁鸟类点位数据在 Google地图中进行人工校正, 然后将校正后的数据 在ArcGIS 中直接落位到受胁鸟类栖息地分布格局 上，并统计分布在各级栖息地中的点位比例，验证 分布格局的有效性。

\subsection{3 重要栖息地在三类区域的分布及其受保护 比例}

使用城市建成区、乡村生境区和自然生境区的 空间数据提取计算各级重要栖息地分布在其中的 面积比例。分别使用自然保护区、生态保护红线和 限制建设线的空间数据提取计算 3 种保护潜力区覆 盖城市建成区、乡村生境区和自然生境区的面积比 例以及覆盖各级栖息地的面积比例。

\section{结果}

\section{1 受胁鸟类栖息地空间分布}

北京市域受胁鸟类栖息地如图2所示。受胁鸟 类栖息地共计 $5,041.30 \mathrm{~km}^{2}$, 占北京市域总面积的 $30.7 \%$ ，其中 $70 \%$ 以上分布在乡村生境区。

一类栖息地中，林地类栖息地面积最大，占受 胁鸟类栖息地总面积的 $59.05 \%$; 耕地面积次之, 占 $26.91 \%$; 水域面积占 $8.02 \%$; 草地和未利用地分别 占3.27\%和 $2.74 \%$ 。二类栖息地中, 有林地占地面积 最大 $(49.59 \%)$; 旱地次之, 占 $26.90 \%$; 其他林地第 三，占7.33\%。一类和二栖息地中的受胁鸟类栖息地 面积及其占受胁鸟类栖息地总面积的比例详见附 录2。

\section{2 受胁鸟类丰富度分布格局、评级及验证}

受胁鸟类丰富度分布格局验证结果如附录3。 结果显示, $83.48 \%$ 的验证鸟类点位落在受胁鸟类栖 息地分布区域中，其中一级关键鸟类栖息地覆盖 $41.74 \%$ 的点位，二级关键栖息地覆盖6.09\%的点位， 三级栖息地覆盖 $5.80 \%$ 的点位，四级栖息地覆盖 $29.57 \%$ 的点位。

北京市域受胁鸟类丰富度分布格局如图3所 示。乡村生境区的大型水库及其周边滩地，城市建 成区的大型绿地、公园，及位于平谷区和通州区的 坑塘水体是受胁鸟类丰富度最高的区域; 其次为高 覆盖度草地和旱地; 有林地和自然生境区的受胁鸟 类丰富度则较低。

一级关键栖息地主要包括了水域中的湖泊、水 库、坑塘以及沼泽地; 二级关键栖息地包括水域中 的河渠、滩地和高覆盖度草地; 三级栖息地则主要 包括各类耕地、灌木林地、中覆盖度/低覆盖度草地; 四级栖息地则包括林地、疏林地以及裸岩、裸土、 沙地等。

各级栖息地占北京全市面积的比例及其在城 市建成区、乡村生境区和自然生境区的分布比例如 表1所示。结果显示, $80 \%$ 以上的一级、二级关键栖 息地和三级栖息地，以及 $70 \%$ 以上的四级栖息地位 于乡村生境区； $10.61 \%$ 的二级关键栖息地位于城市 建成区; 一级和二级关键栖息地在自然生境区中分 布很少，四级栖息地则有超过 $20 \%$ 位于自然生境 区。

表1 受胁鸟类各级栖息地在城市建成区、乡村生境区和自 然生境区的分布比例及其占市域面积的比例

Table 1 The coverage ratio of the habitats of threatened bird to urban, rural and natural areas and the whole area of Beijing

\begin{tabular}{|c|c|c|c|c|}
\hline $\begin{array}{l}\text { 分区 } \\
\text { Types of landscape }\end{array}$ & $\begin{array}{l}\text { 一级关键栖 } \\
\text { 息地 The } \\
\text { 1st level key } \\
\text { habitats }\end{array}$ & $\begin{array}{l}\text { 二级关键栖 } \\
\text { 息地 The } \\
\text { 2nd level } \\
\text { key habitats }\end{array}$ & $\begin{array}{l}\text { 三级栖 } \\
\text { 息地 } \\
\text { The 3rd } \\
\text { level } \\
\text { habitats }\end{array}$ & $\begin{array}{l}\text { 四级栖 } \\
\text { 息地 } \\
\text { The 4th } \\
\text { level } \\
\text { habitats }\end{array}$ \\
\hline 城市建成区 Urban area & $1.87 \%$ & $10.61 \%$ & $2.98 \%$ & $4.88 \%$ \\
\hline 乡村生境区 Rural area & $95.64 \%$ & $86.32 \%$ & $95.64 \%$ & $74.72 \%$ \\
\hline 自然生境区 Natural area & $2.49 \%$ & $3.06 \%$ & $1.37 \%$ & $20.40 \%$ \\
\hline $\begin{array}{l}\text { 北京市域 The whole } \\
\text { area of Beijing }\end{array}$ & $1.52 \%$ & $1.10 \%$ & $7.08 \%$ & $20.33 \%$ \\
\hline
\end{tabular}




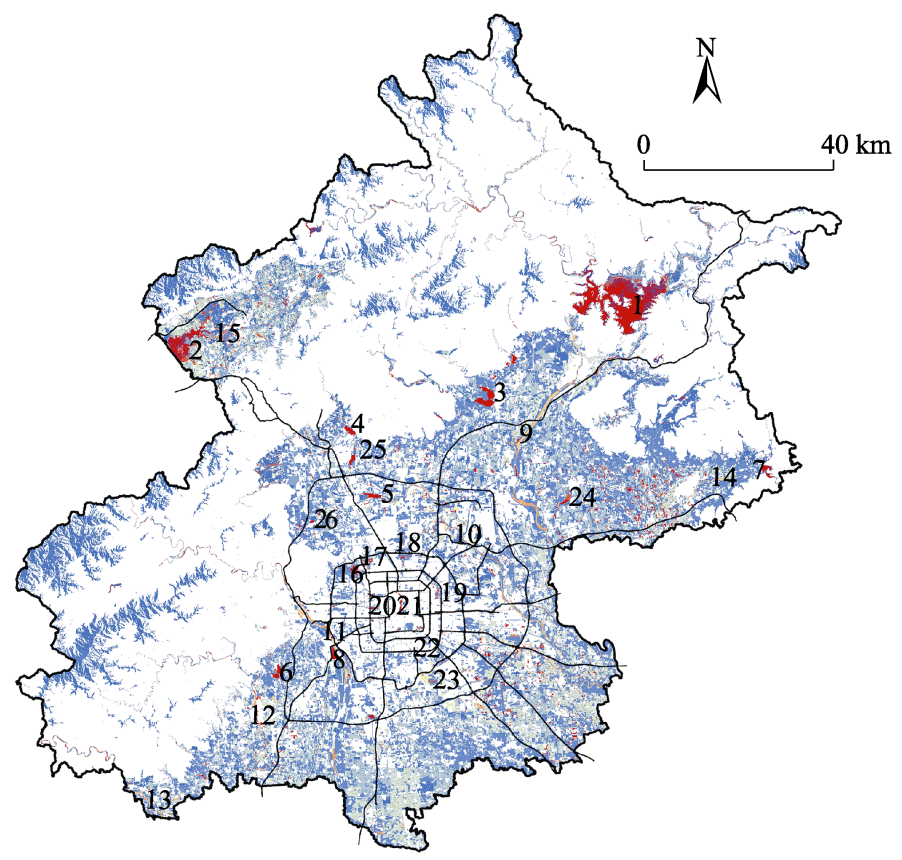

图例 Legend

$\square$ 北京市域边界 Boundary of Beijing
一 主要道路 Main roads
受胁鸟类丰富度
The richness of threatened birds
18
1

图3 北京市域受胁鸟类丰富度的空间分布格局。一级关键栖息地分别是: 1: 密云水库; 2: 官厅水库; 3: 怀柔水库; 4: 十三 陵水库; 5: 沙河水库; 6: 崇青水库; 7: 海子水库; 8: 大宁水库及其周边的滩地; 9: 潮白河; 10: 温榆河; 11: 永定河; 12: 大 石河; 13: 拒马河; 14: 泃河; 15: 妫水河等河渠; 16: 㯺和园; 17: 圆明园; 18: 奥林匹克森林公园; 19: 朝阳公园; 20: 玉渊潭 公园; 21: 中南海、北海和后海; 22: 龙潭西湖公园; 23: 麇鹿苑; 24: 汉石桥湿地市级自然保护区; 25: 白浮泉公园; 26: 翠湖 国家城市湿地公园等城市绿地水体。

Fig. 3 A map of richness pattern of 30 threatened bird species and the habitat classification. The 1st level key habitats are as follows. 1, Miyun Reservoir; 2, Guanting Reservoir; 3, Huairou Reservoir; 4, Shisanling Reservoir; 5, Shahe Reservoir; 6, Chongqing Reservoir; 7, Haizi Reservoir; 8, Daning Reservoir; 9, Chaobai River; 10, Wenyu River; 11, Yongding River; 12, Dashi River; 13, Juma River; 14, Juhe River; 15 Guishui River; waters in urban green spaces, 16, The Summer Palace; 17, The Yuanmingyuan Park; 18, Olympic Forest Park; 19, Chaoyang Park; 20, Yuyuantan Park; 21, Zhongnanhai, Beihai and Houhai; 22, Longtan West Lake Park; 23, Miluyuan Park; 24, Hanshiqiao Municipal Wetland Nature Reserve; 25, Baifuquan Park; 26, Cuihu National Urban Wetland Park.

\section{3 保护潜力区对北京市域的覆盖比例}

自然保护区、生态保护红线和限制建设线的覆 盖面积分别占北京市域面积的 $4.51 \%$ 、26.83\%和 $74.40 \%$ 。三类保护潜力区对城市建成区、乡村生境 区和自然生境区的覆盖比例如表2所示。北京市域 的自然保护区覆盖率(4.51\%)远低于全国平均水平 (15.33\%) (http://www.mee.gov.cn/ywgz/zrst bh/zrbhd jg/201905/P020190514616282907461.pdf); 城市建 成区受保护潜力区覆盖面积比例为 $5.75 \%$; 生态保 护红线覆盖了北京超过15\%的乡村生境区和近 $50 \%$ 的自然生境区; 限制建设线覆盖了 $63.20 \%$ 的乡村生 境区和几乎所有自然生境区。

\section{4 重要栖息地保护空缺}

三类保护潜力区对 4 个级别栖息地的覆盖比例 如表3所示。结果显示, 自然保护区在北京市域内对 一级关键栖息地的覆盖比例近 $10 \%$, 对二级关键栖
息地和三级栖息地的覆盖比例则极低(分别为 $1.66 \%$ 和0.39\%)。生态保护红线覆盖了北京市域超过50\% 的一级关键栖息地和近 $1 / 3$ 的二级关键栖息地, 但

表2 三类保护潜力区占北京市域比例及对城市建成区、乡 村和自然生境区覆盖比例

Table 2 The coverage ratio of three categories of potential areas for conservation (PAC) to the whole area of Beijing, urban, rural and natural areas

\begin{tabular}{lllll}
\hline $\begin{array}{l}\text { 保护潜力区 } \\
\text { PAC }\end{array}$ & $\begin{array}{l}\text { 北京市域 } \\
\text { Whole area } \\
\text { of Beijing }\end{array}$ & $\begin{array}{l}\text { 城市建成区 } \\
\text { Urban area }\end{array}$ & $\begin{array}{l}\text { 乡村生境区 自然生境区 } \\
\text { Rural area } \\
\text { Natural area }\end{array}$ \\
\hline $\begin{array}{l}\text { 自然保护区 } \\
\text { Natural reserve }\end{array}$ & $4.51 \%$ & $0.17 \%$ & $0.69 \%$ & $9.46 \%$ \\
$\begin{array}{l}\text { 生态保护红线 } \\
\text { 26.83\% }\end{array}$ & $0.65 \%$ & $15.15 \%$ & $44.77 \%$ \\
$\begin{array}{l}\text { Ecological } \\
\text { protection red } \\
\text { line }\end{array}$ & & & & \\
$\begin{array}{l}\text { 限制建设线 } \\
\text { Construction } \\
\text { control line }\end{array}$ & $74.40 \%$ & $4.93 \%$ & $63.20 \%$ & $99.50 \%$ \\
\hline
\end{tabular}


表3 三类保护潜力区对各级栖息地的保护比例

Table 3 The coverage ratio of three categories of potential areas for conservation (PAC) to the four levels of habitats

\begin{tabular}{|c|c|c|c|c|}
\hline $\begin{array}{l}\text { 保护潜力区 } \\
\text { PAC }\end{array}$ & $\begin{array}{l}\text { 一级关键栖 } \\
\text { 息地 } 1 \text { st } \\
\text { level key } \\
\text { habitats }\end{array}$ & $\begin{array}{l}\text { 二级关键栖 } \\
\text { 息地 2nd } \\
\text { level key } \\
\text { habitats }\end{array}$ & $\begin{array}{l}\text { 三级栖息地 } \\
\text { 3rd level } \\
\text { habitats }\end{array}$ & $\begin{array}{l}\text { 四级栖息地 } \\
\text { 4th level } \\
\text { habitats }\end{array}$ \\
\hline $\begin{array}{l}\text { 自然保护区 } \\
\text { Natural reserve }\end{array}$ & $e^{9.01 \%}$ & $1.66 \%$ & $0.39 \%$ & $5.73 \%$ \\
\hline $\begin{array}{l}\text { 生态保护红线 } \\
\text { Ecological } \\
\text { protection red } \\
\text { line }\end{array}$ & $59.82 \%$ & $31.40 \%$ & $3.83 \%$ & $19.48 \%$ \\
\hline $\begin{array}{l}\text { 限制建设线 } \\
\text { Construction } \\
\text { control line }\end{array}$ & $75.67 \%$ & $56.56 \%$ & $68.87 \%$ & $69.73 \%$ \\
\hline
\end{tabular}

覆盖的三级栖息地比例较低(3.83\%)。限制建设线覆 盖了 $3 / 4$ 以上的一级关键栖息地、 $50 \%$ 以上的二级关 键栖息地以及大部分三、四级栖息地。

限制建设线已经覆盖了 $50 \%$ 以上的受胁鸟类栖 息地, 然而, 31.17\%的一级关键栖息地, 66.94\%的二 级关键栖息地, $95.77 \%$ 的三级栖息地和 $74.79 \%$ 的四 级栖息地未被自然保护区和生态保护红线覆盖。上 述空缺地块位置分布如图4所示, 其所属一类、二类 栖息地类型及相应面积如表4所示。结果显示, 未被
自然保护区和生态保护红线覆盖的受胁鸟类一级 关键栖息地主要是湖泊、水库、坑塘、滩地和沼泽 地等湿地和高覆盖度草地, 二级关键栖息地主要是 河渠、坑塘等湿地和高覆盖度草地、有林地和旱地, 而三级栖息地主要是旱地、有林地和灌木林, 四级 栖息地主要是有林地、其他林地和旱地。

\section{3 讨论}

\section{1 城市建成区受胁鸟类栖息地保护}

分析结果显示有近 $2 \%$ 的受胁鸟类一级关键栖 息地和约 $11 \%$ 的二级关键栖息地位于城市建成区。 这些栖息地类型主要为具有悠久历史的皇家园林 或者近几十年兴建的大型城市公园绿地及水域。国 外研究显示, 面积10-35 ha的公园即可维系其所在 城市的大部分常见鸟类 (Fernandez-Juricic \& Jokimäki, 2001); 城市建成区也可为濒危物种提供 栖息地(Jokimäki et al, 2018)。国内研究显示，北京 城市建成区内的大型城市绿地可以为超过 150 种鸟 类提供季节性或永久性栖息地(陈志强等, 2010; 闻 丞等, 2014; 刘洋等, 2015; 滑荣等, 2019)。

北京城市建成区内的中南海、北海、后海、䝠

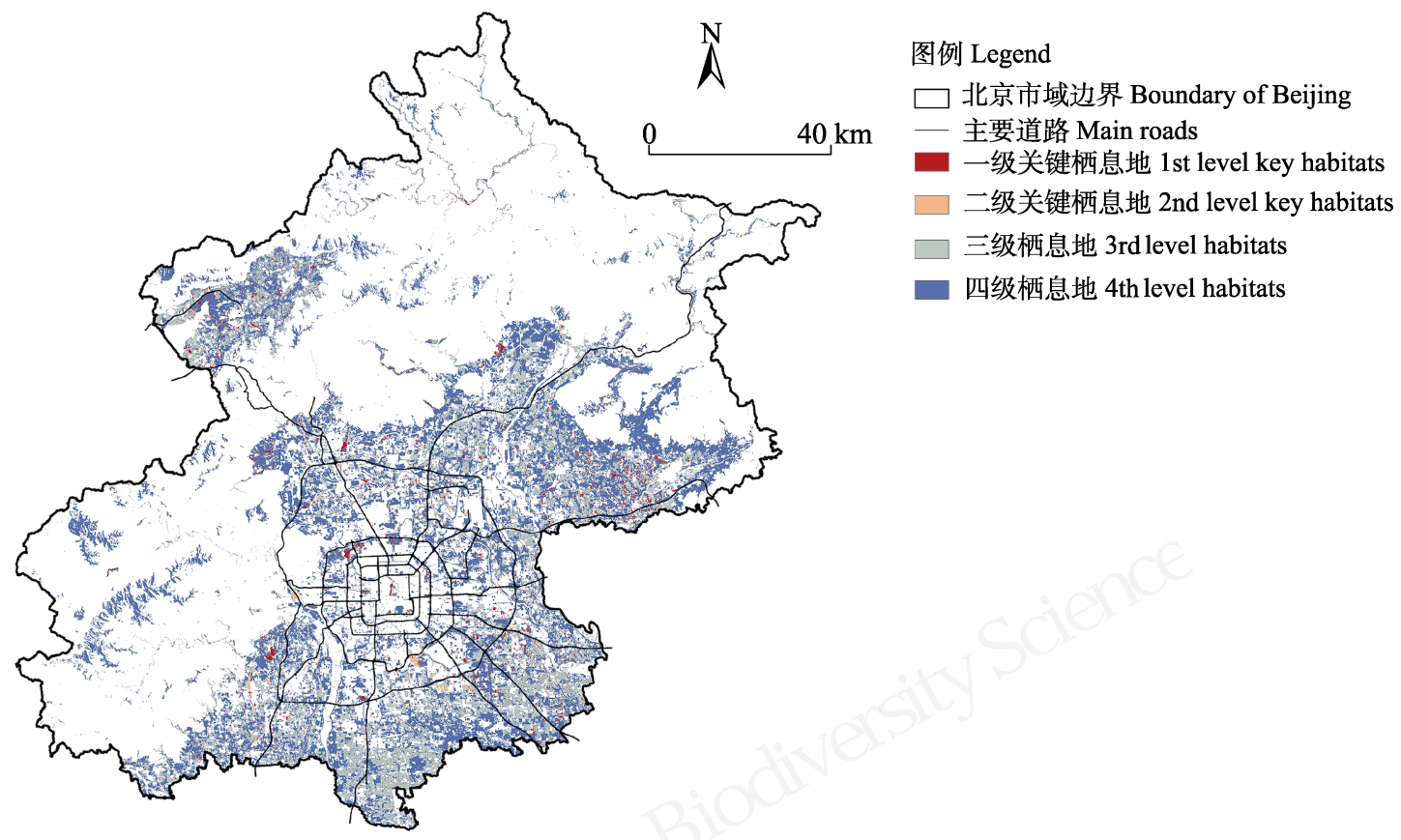

图4 未被自然保护区和生态保护红线覆盖的受胁鸟类栖息地空间分布

Fig. 4 The distribution map of the habitats of threatened birds uncovered by nature reserves and the ecological protection red line 
表4 未被自然保护区和生态保护红线覆盖的受胁鸟类一级关键、二级关键、三级和四级栖息地类型及其面积 $\left(\mathrm{km}^{2}\right)$

Table 4 The types and area $\left(\mathrm{km}^{2}\right)$ of the habitats of threatened birds uncovered by the nature reserves and the ecological protection red line

\begin{tabular}{|c|c|c|c|c|c|}
\hline $\begin{array}{l}\text { 一类栖息地 } \\
\text { Habitat I }\end{array}$ & $\begin{array}{l}\text { 二类栖息地 } \\
\text { Habitat II }\end{array}$ & $\begin{array}{l}\text { 一级关键栖息地 } \\
\text { 1st level key habitats }\end{array}$ & $\begin{array}{l}\text { 二级关键栖息地 } \\
\text { 2nd level key habitats }\end{array}$ & $\begin{array}{l}\text { 三级栖息地 } \\
\text { 3rd level habitats }\end{array}$ & $\begin{array}{l}\text { 四级栖息地 } \\
\text { 4th level habitats }\end{array}$ \\
\hline \multirow{5}{*}{$\begin{array}{l}\text { 水域 } \\
\text { Waters }\end{array}$} & 河渠 River & 0.600 & 33.434 & 8.409 & 17.644 \\
\hline & 湖泊 Lake & 16.765 & 1.884 & 0.162 & 0.783 \\
\hline & 水库 Reservoir & 7.720 & 0.345 & 0.054 & 3.853 \\
\hline & 坑塘 Pool & 39.389 & 9.231 & 1.167 & 3.940 \\
\hline & 滩地 Shallows & 3.205 & 1.152 & 0.184 & 0.597 \\
\hline \multirow{2}{*}{$\begin{array}{l}\text { 耕地 } \\
\text { Farmlands }\end{array}$} & 水田 Paddy field & 0.002 & 0.022 & 0.483 & 0.050 \\
\hline & 旱地 Dry farmland & 1.489 & 6.941 & 984.528 & 174.111 \\
\hline \multirow{4}{*}{$\begin{array}{l}\text { 林地 } \\
\text { Woodlands }\end{array}$} & 灌木林 Shrub land & 0.138 & 0.192 & 21.947 & 37.895 \\
\hline & 疏林地 Open forest & 0.092 & 0.236 & 0.274 & 33.018 \\
\hline & 有林地 Woodland & 2.716 & 8.152 & 32.228 & $1,479.720$ \\
\hline & 其他林地 Other woodland & 0.564 & 0.612 & 4.678 & 319.142 \\
\hline \multirow[t]{3}{*}{$\begin{array}{l}\text { 草地 } \\
\text { Grasslands }\end{array}$} & $\begin{array}{l}\text { 高覆盖度草地 Grassland with high } \\
\text { coverage }\end{array}$ & 19.786 & 39.669 & 1.054 & 15.808 \\
\hline & $\begin{array}{l}\text { 中覆盖度草地 Grassland with } \\
\text { medium coverage }\end{array}$ & 0.125 & 5.969 & 11.621 & 8.328 \\
\hline & $\begin{array}{l}\text { 低覆盖度草地 Grassland with low } \\
\text { coverage }\end{array}$ & 0.035 & 1.648 & 7.772 & 7.060 \\
\hline \multirow{4}{*}{$\begin{array}{l}\text { 未利用地 } \\
\text { Unutilized } \\
\text { lands }\end{array}$} & 沼泽地 Marsh & 3.439 & 0.527 & 0.083 & 0.579 \\
\hline & 裸土地 Bare land & 0.149 & 0.398 & 0.653 & 86.917 \\
\hline & 沙地 Sand land & 0.010 & 0.013 & 0.037 & 0.866 \\
\hline & 裸岩石质地 Bare rock & 0.008 & 0 & 0.002 & 2.239 \\
\hline 合计 Total & & 96.230 & 110.427 & $1,075.334$ & $2,192.550$ \\
\hline
\end{tabular}

和园、圆明园、奥林匹克森林公园、朝阳公园、玉 渊潭等大型绿地为大量鸟类提供了适宜栖息地, 包 括青头潜鸭(Aythya baeri)、褐头冻、黄胸旣(Emberiza aureola)等受胁鸟种。上述绿地面积均在35 ha以上, 均有成为大多数鸟类、小型哺乳动物、两栖和爬行 动物等类群稳定栖息地的潜质。但由于人类游悡空 间和活动对栖息地的分割和干扰，以及管理措施等 方面的原因, 目前建成区内大部分栖息地的质量较 差, 鸟类多样性较低(黄越, 2015)。

由于城市建成区具有以人为导向的社会、经济 属性, 北京市的3类保护潜力区都极少涉及城市建 成区(小于5\%), 相应的保护政策目前也难以直接惠 及该区域的生物多样性。自然保护区和生态保护红 线尚未覆盖位于城市建成区内及其外围的公园, 尤 其是具有悠久历史的皇家园林和近年建设拥有大 面积水体的大型城市绿地。2019年, 北京市发布了 《鸟类多样性及栖息地质量评价技术规程》地方标 准, 明确要求在城市绿地和乡村生境区域针对受胁
鸟类、国家和北京市重点保护鸟类的特定栖息地要 求, 开展栖息地质量评价、恢复设计和管理。在此 基础上，建议进一步细化对建成区大型绿地的分区 管理规范，划定生物多样性保育区，保证现有和未 来新建的大型城市绿地中能够保有 $10 \mathrm{ha}$ 或以上面 积的完整栖息地, 包含一定面积的水体、沼泽、滩 地和高覆盖草地; 降低人为活动干扰; 结合绿地养 护和提升工程, 营造适宜各类生物栖息的生境, 特 别是水域栖息地。

\section{2 乡村生境区受胁鸟类栖息地保护}

北京受胁鸟类栖息地有 $81.14 \%$ 位于乡村生境 区(图2); 其一级关键、二级关键和三级栖息地在乡 村生境区中的比例均超过或接近 $90 \%$ (表1), 邻近 河流的耕地、灌木林、水域和沼泽地是关键的一级 和二级栖息地。然而, 由于中国仍然处在城市化进 程中, 农业人口向城市转移, 大城市周边的乡村地 区逐渐向城市转变(http://www.gov.cn/zhengce/cont ent/2020-03/12/content_5490385.htm)。乡村生境区 
是连接城市建成区和自然生境区的过渡地带, 在城 市扩张的过程中, 原本属于乡村的栖息地将变成建 成区的栖息地，导致乡村生境区的城市化(Seto et al, 2012)。由此可见，对于北京市域受胁鸟类保护成效， 乡村区域是有决定性作用的重点区域。

自然保护区对乡村生境区覆盖比例为 $0.69 \%$, 主要贡献来自野鸭湖、汉石桥两个湿地类型的自然 保护区。生态保护红线划定区域对乡村生境区的覆 盖比例为 $15.15 \%$, 主要贡献来自于潮白河、温榆河、 永定河等河流及两岸防护绿地。限制建设线划定区 域对乡村生境区的覆盖比例为63.20\%, 主要贡献包 括基本农田、防护林等。乡村生境区受具有严格生 态保护措施的自然保护区和生态保护红线覆盖不 足。《北京城市总体规划(2016-2035年)》中的9条绿 色楔形廊道大部分位于乡村生境区, 因此加强乡村 生境区生物多样性的研究和保护, 制定适宜的生物 多样性管理措施，有助于实现总体规划中对城乡一 体化发展的要求, 避免乡村生境区的重要栖息地在 此过程中被忽视。

鉴于一、二级关键栖息地主要是水域及周边的 滩地、高覆盖度草地, 在2013年开始实施的《北京 市湿地保护条例》基础上，应进一步严格保证水域、 沼泽地、高覆盖草地等关键栖息地总面积不减少, 且其质量在未来能够得到提升, 这将为受胁鸟类、 两栖类、濒危水生昆虫、鱼类等生物类群提供庇护 所。对于接近河道生态保护红线的灌木林、高覆盖 草地、水域和沼泽地, 建议未来将其纳入生态保护 红线范围内。

农田是一些大型受胁鸟类的重要栖息地(Li et al, 2020)。据鸟类分布数据, 鹤(Grus sp.)、大鸫 (Otis tarda)、雁(Anser sp.) 等受胁鸟类在冬季和迁徙季, 多利用位于水库附近的农田受食。大片此类区域在 过去 3 年的时间内, 由于库滨带严禁种植业发展和 水土保持林地的建设趋于消失。北京目前保有约 1,000 km² 基本农田(http://www.beijing.gov.cn/gong kai/guihua/wngh/cqgh/201907/t20190701_100008.ht $\mathrm{ml}$ ), 占北京市域面积的 $6.10 \%$ 。无论是出于粮食安 全, 还是受胁鸟类保护的考虑, 特别建议维持位于 大型水面附近基本农田的粮食种植功能。

对于目前属于三、四级栖息地的各类林地，应
结合未来“平原造林”和建成区外围新建的大型绿地 空间，依据相关地方标准，增加适宜受胁鸟类栖息 的灌木林、高覆盖度草地，而不是单纯种植乔木。 尤其对于平原地区树种单一的大面积人工林，应结 合更新抚育工作，增加食源和蜜源树种，以及灌木 和草地栖息地。

\section{3 自然生境区的栖息地保护}

分析结果显示, 生态保护红线划定和限制建设 线划定区域分别占自然生境区的近 $44.77 \%$ 和 99.50\%。总体而言，自然生境区受到了较好保护。 尽管仅有不足 $5 \%$ 的一、二级受胁鸟类关键栖息地分 布于北京市域自然生境区，但这一广大区域为其他 物种如大、中型哺乳动物预留了充足的栖息空间。

\section{总结}

使用指标物种丰富度分布模型指示保护区域 具有争议(Lawton \& Gaston, 2001; Moradi et al, 2019)。但不可否认的是，濒危物种分布空间与人类 高密度聚居区具有空间一致性，濒危物种保护议题 显得尤为复杂(Luck, 2007)。以往在人口高密度聚居 的城市区域，开展物种栖息地保护的常用形式为 “生态网络”，如欧盟的自然 2000 (Natura 2000) (Pellissier et al, 2020)。本文基于全国鸟类分布模型， 采用“物种-栖息地”方法在高密度人口聚居区识别 濒危物种的栖息地(Lei et al, 2006)并掩膜鸟类分布 模型，再采用不同来源鸟类点位数据对预测空间分 布进行验证，从可行性上为在人口高密度地区识别 濒危物种保护区域提供了另一种技术路线。

高密度人口聚居区的土地利用颇为精细化，因 此, 在人口高密度地区的濒危物种保护措施需要融 入土地利用和管理行为中。首先，需要将濒危物种 拟定保护区域纳入城市总体规划中，与现有具有保 护性质的分区规划进行整合，甚至影响分区规划; 其次，特别针对城市建成区和乡村生境区，受胁鸟 类栖息地的保护需要融入现有各类土地的具体管 理措施中，以保证城市土地在为人类生活提供空间 和资源的同时也为野生动物提供必要的栖息环境。

\section{参考文献}

Beijing Municipal Bureau Statistics, Survey Office of the National Bureau of Statistics in Beijing (2019) Beijing 
Statistical Yearbook 2019. China Statistics Press, Beijing. (in Chinese) [北京市统计局, 国家统计局北京调查总队 (2019) 北京统计年鉴2019. 中国统计出版社, 北京.]

Chen ZQ, Fu JP, Zhao XR, Ding CQ (2010) The construction of birds in Yuanmingyuan Relic Park, Beijing. Chinese Journal of Zoology, 45(4), 21-30. (in Chinese with English abstract) [陈志强, 付建平, 赵欣如, 丁长青 (2010) 北京 圆明园遗址公园鸟类组成. 动物学杂志, 45(4), 21-30.]

CBD (Convention on Biological Diversity) (2011) Conference of the Parties Decision X/2: Strategic Plan for Biodiversity 2011-2020. http://www.cbd.int/decision/cop/?id=12268. (accessed on 2020-03-20)

Dinerstein E, Olson D, Joshi A, Vynne C, Burgess ND, Wikramanayake E, Hahn N, Palminteri S, Hedao P, Noss R, Hansen M, Locke H, Ellis EC, Jones B, Barber CV, Hayes R, Kormos C, Martin V, Crist E, Sechrest W, Price L, Baillie JEM, Weeden D, Suckling K, Davis C, Sizer N, Moore R, Thau D, Birch T, Potapov P, Turubanova S, Tyukavina A, de Souza N, Pintea L, Brito JC, Llewellyn OA, Miller AG, Patzelt A, Ghazanfar SA, Timberlake J, Klöser H, Shennan-Farpón Y, Kindt R, Lillesø JPB, van Breugel P, Graudal L, Voge M, Al-Shammari KF, Saleem M (2017) An ecoregion-based approach to protecting half the terrestrial realm. BioScience, 67, 534-545.

Ding ZG (2009) Construction Restriction Planning of Beijing (2006-2020). Jiangsu Urban Planning, (9), 38-43. (in Chinese) [丁志刚 (2009) 北京市限建区规划 (2006年 -2020年). 江苏城市规划, (9), 38-43.]

eBird Basic Dataset (2020) Version: EBD_relMay-2020. Cornell Lab of Ornithology, Ithaca, New York.

Editorial Committee of Zoology of China, Chinese Academy of Sciences (1978-2010) Fauna of China (Avifauna) Volume 1-14. Science Press, Beijing. (in Chinese) [中国科学院中 国动物志编辑委员会 (1978-2010) 中国动物志(鸟纲), 1-14卷. 科学出版社, 北京.]

Fernández-Juricic E, Jokimäki J (2001) A habitat island approach to conserving birds in urban landscapes: Case studies from southern and northern Europe. Biodiversity \& Conservation, 10, 2023-2043.

He Y (2008) Space restriction of urban-rural construction and development - Construction restriction planning of Beijing. China Construction, (9), 15-17. (in Chinese) [何永 (2008) 城乡建设发展的空间限制——北京市限建区规划. 中华 建设, (9), 15-17.]

Herrando S, Weiserbs A, Quesada J, Ferrer X, Paquet JY (2012) Development of urban bird indicators using data from monitoring schemes in two large European cities. Animal Biodiversity and Conservation, 35, 141-150.

Hu RC, Wen C, Gu YY, Wang H, Gu L, Shi XY, Zhong J, Wei M, He FQ, Lü Z (2017) A bird's view of new conservation hotspots in China. Biological Conservation, 211, 47-55.

Hua R, Cui DY, Li SH, Liu J, Yan S, Yang J, Zhang CL, Li XG (2019) Investigations on bird diversity of the Summer Palace in Beijing, China. Chinese Journal of Wildlife, 40, 945-956. (in Chinese with English abstract) [滑荣, 崔多英, 李淑红, 刘佳, 颜素, 杨静, 张成林, 李晓光 (2019) 北
京臨和园鸟类多样性调查. 野生动物学报, 40, 945-956.]

Huang Y (2015) The methodology of bird habitats' making and planning at Beijing urban green spaces. Tsinghua University, Beijing. (in Chinese with English abstract) [黄越 (2015) 北京城市绿地鸟类生境规划与营造方法研究. 清 华大学, 北京.]

Huang Y, Zhao YZ, Li SH, von Gadow K (2015) The effects of habitat area, vegetation structure and insect richness on breeding bird populations in Beijing urban parks. Urban Forestry \& Urban Greening, 14, 1027-1039.

International Union for Conservation of Nature and Natural Resources (2020) The IUCN Red List of Threatened Species. Version 2020-1. https://www.iucnredlist.org. (accessed on 2020-07-11)

Jokimäki J, Suhonen J, Kaisanlahti-Jokimäki ML (2018) Urban core areas are important for species conservation: A European-level analysis of breeding bird species. Landscape and Urban Planning, 178, 73-81.

Lawton JH, Gaston KJ (2001) Indicator species. In: Encyclopedia of Biodiversity, 437-450. Elsevier, Amsterdam.

Lei FM, Zhao HF, Yin ZH (2006) Distribution pattern of endangered bird species in China. Integrative Zoology, 1, 162-169.

Lepage D (2021) Avibase-The World Bird Database. http://avibase.bsc-eoc.org/checklist.jsp?region $=\mathrm{CNbj}$. (accessed on 2020-03-20)

Li L, Hu RC, Huang JK, Bürgi M, Zhu ZY, Zhong J, Lü Z (2020) A farmland biodiversity strategy is needed for China. Nature Ecology \& Evolution, 4, 772-774.

Liu Y, Li Q, Zhang MQ (2015) Dynamic change in bird community in the Temple of Heaven in Beijing. Ecological Science, 34(4), 64-70. (in Chinese with English abstract) [刘洋, 李强, 张明庆 (2015) 北京天坛公园鸟类群落的 动态变化研究. 生态科学, 34(4), 64-70.]

Long Y, He Y, Liu X, Du LQ (2006) Planning of the controlled-construction area in Beijing: Establishing urban expansion boundary. City Planning Review, 30(12), 20-26. (in Chinese with English abstract) [龙瀛, 何永, 刘欣, 杜 立群 (2006) 北京市限建区规划: 制订城市扩展的边界. 城市规划, 30(12), 20-26.]

Luck GW (2007) A review of the relationships between human population density and biodiversity. Biological Reviews, 82, 607-645.

MacKinnon J, Phillipps K, He FQ (2000) A Field Guide to the Birds of China. Hunan Education Press, Changsha. (in Chinese) [MacKinnon J, Phillipps K, 何芬奇 (2000) 中国 鸟类野外手册. 湖南教育出版社, 长沙.]

Mittermeier RA, Mittermeier CG, Gil PR (1999) Megadiversity: Earth's biologically wealthiest nations. Chelonian Conservation and Biology, 3, 537.

Moradi S, Ilanloo SS, Kafash A, Yousefi M (2019) Identifying high-priority conservation areas for avian biodiversity using species distribution modeling. Ecological Indicators, 97, 159-164.

Pellissier V, Schmucki R, Pe'Er G, Aunins A, Brereton TM, Brotons L, Carnicer J, Chodkiewicz T, Chylarecki P, del 
Moral JC, Escandell V, Evans D, Foppen R, Harpke A, Heliölä J, Herrando S, Kuussaari M, Kühn E, Lehikoinen A, Lindström Å, Moshøj CM, Musche M, Noble D, Oliver TH, Reif J, Richard D, Roy DB, Schweiger O, Settele J, Stefanescu C, Teufelbauer N, Touroult J, Trautmann S, van Strien AJ, van Swaay CAM, van Turnhout C, Vermouzek Z, Voříšek P, Jiguet F, Julliard R (2020) Effects of Natura 2000 on nontarget bird and butterfly species based on citizen science data. Conservation Biology, 34, 666-676.

Seto KC, Güneralp B, Hutyra LR (2012) Global forecasts of urban expansion to 2030 and direct impacts on biodiversity and carbon pools. Proceedings of the National Academy of Sciences, USA, 109, 16083-16088.

Song K, Mi CR, Zhao YZ, Yang N, Sun YH, Xu JL (2016) Modeling habitat factors and suitability for the brown eared pheasant (Crossoptilon mantchuricum) in Baihuashan National Nature Reserve, Beijing. Chinese Journal of Zoology, 51, 363-372. (in Chinese with English abstract) [宋凯, 宓春荣, 赵玉泽, 杨南, 孙悦华, 徐基良 (2016) 百花山国家级自然保护区褐马鸡栖息地利用分析. 动物 学杂志, 51, 363-372.]

Tang XP, Luan XF (2017) Developing a nature protected area system composed mainly of national parks. Forest Resources Management, (6), 1-8. (in Chinese with English abstract) [唐小平, 奕晓峰 (2017) 构建以国家公园为主 体的自然保护地体系. 林业资源管理, (6), 1-8.]

Wen C, Gu L, Wang H, Lü Z, Hu RC, Zhong J (2015) GAP analysis on national nature reserves in China based on the distribution of endangered species. Biodiversity Science, 23, 591-600. (in Chinese with English abstract) [闻丞, 顾垒, 王吴，吕植，胡若成，钟嘉 (2015) 基于最受关注濒危物 种分布的国家级自然保护区空缺分析. 生物多样性, 23, 591-600.]

Wen C, Han D (2013) Raptor migration monitoring in the spring of 2009 at Baiwangshan, Beijing. Chinese Birds, 4, 319-327.

Wen C, Han D, Li S, Shen XL, Chen W, Wang H, Zhu XJ, Xiao LY, Liu MQ, Lü Z (2014) Community structure of birds at Yanyuan, Peking University. Acta Scientiarum
Naturalium Universitatis Pekinensis, 50, 416-428. (in Chinese with English abstract) [闻丞, 韩冬, 李晟, 申小莉, 陈炜, 王吴, 朱小健, 肖凌云, 刘美琦, 吕植 (2014) 北 京大学燕园鸟类组成. 北京大学学报(自然科学版), 50, 416-428.]

Zhang GG, Zhang ZW, Yang FY, Li SG (2010) Habitat selection of brown-eared pheasant at the Wulushan National Nature Reserve of Shanxi, China. Scientia Silvae Sinicae, 46(11), 100-103. (in Chinese with English abstract) [张国 钢, 张正旺, 杨凤英, 李世广 (2010) 山西五鹿山自然保 护区褐马鸡栖息地的选择. 林业科学, 46(11), 100-103.]

Zhang GG, Zhang ZW, Zheng GM, Li XQ, Li JF, Huang L (2003) Spatial pattern and habitat selection of brown eared pheasant in Wulushan Nature Reserve, Shanxi Province. Biodiversity Science, 11, 303-308. (in Chinese with English abstract) [张国钢, 张正旺, 郑光美, 李晓强, 李俊峰, 黄 雷 (2003) 山西五鹿山褐马鸡不同季节的空间分布与栖 息地选择研究. 生物多样性, 11, 303-308.]

Zhang GG, Zheng GM, Zhang ZW (2004) Reintroduction of brown eared-pheasant Crossoptilon mantchuricum in Wutaishan Mountains of Shanxi, China. Acta Zoologica Sinica, 50, 126-132. (in Chinese with English abstract) [张 国钢, 郑光美, 张正旺 (2004) 山西五台山地区褐马鸡的 再引入. 动物学报, 50, 126-132.]

Zhang GG, Zheng GM, Zhang ZW, Guo JR, Wang JP, Gong SL (2005) Scale-dependent wintering habitat selection by brown-eared pheasant in Luyashan Nature Reserve of Shanxi, China. Acta Ecologica Sinica, 25, 952-957. (in Chinese with English abstract) [张国钢, 郑光美, 张正旺, 郭建荣, 王建平, 宫树龙 (2005) 山西芦芽山褐马鸡越冬 栖息地选择的多尺度研究. 生态学报, 25, 952-957.]

Zheng H, Ouyang ZY (2014) Practice and consideration for ecological red line. Bulletin of Chinese Academy of Sciences, 29, 457-461, 448. (in Chinese with English abstract) [郑华, 欧阳志云 (2014) 生态红线的实践与思 考. 中国科学院院刊, 29, 457-461, 448.]

(责任编委: 杨军 责任编辑: 时意专)

\section{附录 Supplementary Material}

附录1 北京市域受胁鸟类名录及二类栖息地类型

Appendix 1 The list of threatened birds and their habitats ( II ) in Beijing

http://www.biodiversity-science.net/fileup/PDF/2020171-1.pdf

附录2 北京市域受胁鸟类栖息地各类型面积及比例

Appendix 2 The area and proportion of the habitats of threatened birds in Beijing

http://www.biodiversity-science.net/fileup/PDF/2020171-2.pdf

附录3 eBird受胁鸟类点位数据落位空间分布模型比例

Appendix 3 The percent of point data from eBird locating in the distributing model http://www.biodiversity-science.net/fileup/PDF/2020171-3.pdf 
黄越，顾炏芸，阳文锐，闻丞 (2021) 如何在北京充分实现受胁鸟类栖息地保护? 生物多样性, 29(3): 340350.

http://www.biodiversity-science.net/CN/10.17520/biods.2020171

附录 1 北京市域受胁鸟类名录及二类栖息地类型。数据来源: International Union for Conservation of Nature (IUCN), http: //www.iucnredlist.org。CR: 极度濒危; EN: 濒危; VU: 易危。

Appendix 1 The list of threatened birds and their habitats (II) in Beijing. Data sources: International Union for Conservation of Nature (IUCN), http: //www.iucnredlist.org. CR, Critically Endangered; EN, Endangered; VU, Vulnerable.

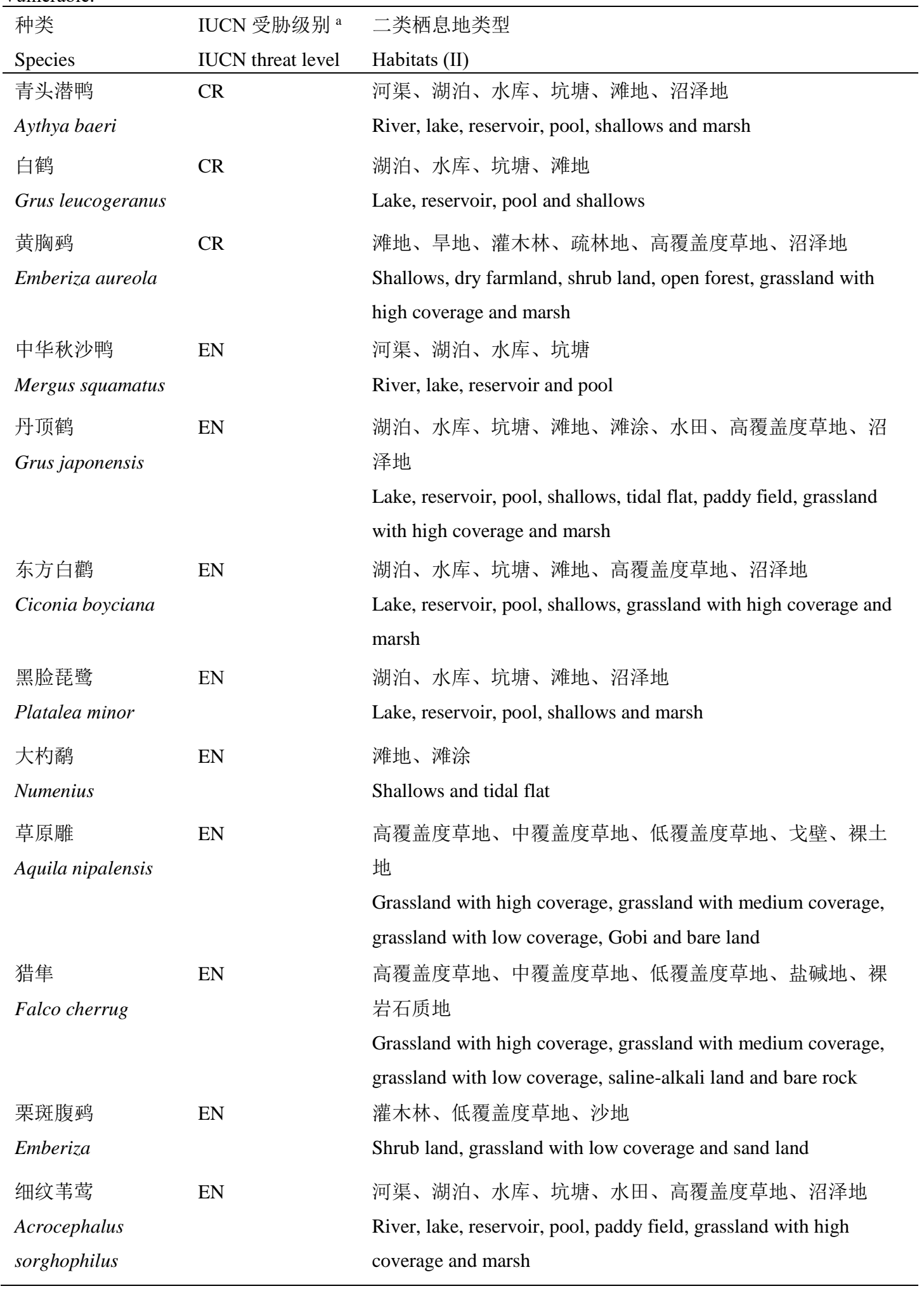


黄越，顾炏芸，阳文锐，闻丞 (2021) 如何在北京充分实现受胁鸟类栖息地保护? 生物多样性, 29(3): 340350 .

http://www.biodiversity-science.net/CN/10.17520/biods.2020171

\begin{tabular}{|c|c|c|}
\hline $\begin{array}{l}\text { 种类 } \\
\text { Species }\end{array}$ & $\begin{array}{l}\text { IUCN 受胁级别 a } \\
\text { IUCN threat level }\end{array}$ & $\begin{array}{l}\text { 二类栖息地类型 } \\
\text { Habitats (II) }\end{array}$ \\
\hline 玉带海雕 & EN & 河渠、湖泊、水库、坑塘、滩地、沼泽地 \\
\hline Haliaeetus & & River, lake, reservoir, pool, shallows and marsh. \\
\hline 白头鹤 & VU & 河渠、湖泊、水库、坑塘、滩地、水田、高覆盖度草地、沼 \\
\hline \multirow[t]{2}{*}{ Grus monacha } & & 泽地 \\
\hline & & $\begin{array}{l}\text { River, lake, reservoir, pool, shallows, paddy field, grassland with } \\
\text { high coverage and marsh }\end{array}$ \\
\hline 大铇 & VU & 旱地、高覆盖度草地、中覆盖度草地、低覆盖度草地、裸土 \\
\hline \multirow[t]{2}{*}{ Otis tarda } & & 地 \\
\hline & & $\begin{array}{l}\text { Dry farmland, grassland with high coverage, grassland with } \\
\text { medium coverage, grassland with low coverage and bare land }\end{array}$ \\
\hline 遗鸥 & VU & 湖泊、水库、坑塘、滩地、滩涂、沼泽地 \\
\hline Ichthyaetus relictus & & Lake, reservoir, pool, shallows, tidal flat and marsh \\
\hline $\begin{array}{l}\text { 白肩雕 } \\
\text { Aquila heliaca }\end{array}$ & VU & $\begin{array}{l}\text { 河渠、水库、坑塘、灌木林、疏林地、有林地、高覆盖度草 } \\
\text { 地、中覆盖度草地、低覆盖度草地、沼泽地 }\end{array}$ \\
\hline Aquila heliaca & & $\begin{array}{l}\text { River, reservoir, pool, shrub land, open forest, woodland, grassland } \\
\text { with high coverage, grassland with medium coverage, grassland } \\
\text { with low coverage and Marsh }\end{array}$ \\
\hline 远东苇莺 & VU & 滩地、水田、沼泽地 \\
\hline Acrocephalus & & Shallows, paddy field and Marsh \\
\hline 褐头冻 & VU & 有林地 \\
\hline Turdus feae & & Woodland \\
\hline 鸿雁 & VU & 湖泊、水库、坑塘、滩地、旱地 \\
\hline Anser cygnoides & & Lake, reservoir, pool, shallows and dry farmland \\
\hline 小白额雁 & VU & 河渠、湖泊、水库、坑塘、滩地、水田、旱地、高覆盖度草 \\
\hline \multirow[t]{3}{*}{ Anser erythropus } & & 地、中覆盖度草地、沼泽地 \\
\hline & & $\begin{array}{l}\text { River, lake, reservoir, pool, shallows, paddy field, dry farmland, } \\
\text { grassland with high coverage, grassland with medium coverage }\end{array}$ \\
\hline & & and marsh \\
\hline 长尾鸭 & VU & 河渠、湖泊、水库、坑塘 \\
\hline Clangula hyemalis & & River, lake, reservoir and pool \\
\hline 红头潜鸭 & VU & 湖泊、水库、坑塘 \\
\hline Aythya ferina & & Lake, reservoir and pool \\
\hline 褐马鸡 & $\mathrm{VU}$ & 灌木林、疏林地、有林地 \\
\hline Crossoptilon & & Shrub land, open forest and woodland \\
\hline 角䴙崕鸟 & VU & 河渠、湖泊、水库、坑塘 \\
\hline Podiceps auritus & & River, lake, reservoir and pool \\
\hline
\end{tabular}


黄越，顾炏芸，阳文锐，闻丞 (2021) 如何在北京充分实现受胁鸟类栖息地保护? 生物多样性, 29(3): 340350 .

http://www.biodiversity-science.net/CN/10.17520/biods.2020171

\begin{tabular}{|c|c|c|}
\hline 种类 & IUCN 受胁级别 a & 二类栖息地类型 \\
\hline Species & IUCN threat level & Habitats (II) \\
\hline 白枕鹤 & VU & 湖泊、水库、坑塘、滩地、水田、旱地、沼泽地 \\
\hline Grus vipio & & $\begin{array}{l}\text { Lake, reservoir, pool, shallows, paddy field, dry farmland and } \\
\text { marsh }\end{array}$ \\
\hline 黄嘴白鹭 & VU & 滩地 \\
\hline Egretta eulophotes & & Shallows \\
\hline 田鴊 & VU & 旱地、灌木林、有林地、其他林地、沼泽地 \\
\hline Emberiza rustica & & Dry farmland, shrub land, woodland, other woodland and marsh \\
\hline $\begin{array}{l}\text { 乌雕 } \\
\text { Clanga clanga }\end{array}$ & VU & $\begin{array}{l}\text { 湖泊、水库、坑塘、滩地、高覆盖度草地、中覆盖度草地、 } \\
\text { 低覆盖度草地、沼泽地 }\end{array}$ \\
\hline & & $\begin{array}{l}\text { Lake, reservoir, pool, shallows, grassland with high coverage, } \\
\text { grassland with medium coverage, grassland with low coverage and } \\
\text { marsh }\end{array}$ \\
\hline 白喉林鹟 & VU & 灌木林、有林地 \\
\hline Cyornis brunneatus & & Shrub land and woodland \\
\hline
\end{tabular}


黄越，顾炏芸，阳文锐，闻丞 (2021) 如何在北京充分实现受胁鸟类栖息地保护? 生物多样性, 29(3): 340350 .

http://www.biodiversity-science.net/CN/10.17520/biods.2020171

附录 2 北京市域受胁鸟类栖息地各类型面积及比例。a 湖泊面积大于等于 $8 \mathrm{hm}^{2}$, 坑塘面积小于 $8 \mathrm{hm}^{2}$; ${ }^{\mathrm{b}}$ 数据来源: http://www.bjwater.gov.cn/bjwater/300795/300797/

638577/index.html。

Appendix 2 The area and proportion of the habitats of threatened birds in Beijing. ${ }^{\text {a }}$ The area of the lake is bigger than or equal to $8 \mathrm{hm}^{2}$, the area of pool is smaller than $8 \mathrm{hm}^{2}$. ${ }^{\mathrm{b}}$ Data source,

http://sw.swj.beijing.gov.cn/bjwater/1281848/1281923/index.html

\begin{tabular}{|c|c|c|c|}
\hline $\begin{array}{l}\text { 一类栖息地 } \\
\text { Habitats (I) }\end{array}$ & $\begin{array}{l}\text { 二类栖息地 } \\
\text { Habitats (II) }\end{array}$ & $\begin{array}{l}\text { 面积 } \\
\text { Area }\left(\mathrm{km}^{2}\right)\end{array}$ & $\begin{array}{l}\text { 百分比 } \\
\text { Proportion }\end{array}$ \\
\hline 水域 & 河渠 River & 128.34 & $2.55 \%$ \\
\hline \multirow[t]{4}{*}{ Waters $(8.02 \%)$} & 湖泊 Lake ${ }^{a}$ & 23.63 & $0.47 \%$ \\
\hline & 水库 Reservoir ${ }^{b}$ & 161.93 & $3.21 \%$ \\
\hline & 坑塘 Pool ${ }^{\mathrm{a}}$ & 60.78 & $1.21 \%$ \\
\hline & 滩地 Shallows & 29.81 & $0.59 \%$ \\
\hline \multirow{2}{*}{$\begin{array}{l}\text { 耕地 } \\
\text { Farmland }(26.91 \%)\end{array}$} & 水田 Paddy Field & 0.64 & $0.01 \%$ \\
\hline & 旱地 Dry farmland & $1,356.02$ & $26.90 \%$ \\
\hline \multirow{4}{*}{$\begin{array}{l}\text { 林地 } \\
\text { Woodlands (59.05\%) }\end{array}$} & 灌木林 Shrub land & 69.77 & $1.38 \%$ \\
\hline & 疏林地 Open forest & 38.20 & $0.76 \%$ \\
\hline & 有林地 Woodland & $2,499.78$ & $49.59 \%$ \\
\hline & 其他林地 Other woodland & 369.38 & $7.33 \%$ \\
\hline \multirow{4}{*}{$\begin{array}{l}\text { 草地 } \\
\text { Grasslands (3.27\%) }\end{array}$} & 高覆盖度草地 & 111.33 & $2.21 \%$ \\
\hline & Grassland with high coverage & & \\
\hline & 中覆盖度草地 & 32.98 & $0.65 \%$ \\
\hline & $\begin{array}{l}\text { Grassland with medium coverage } \\
\text { 低覆盖度草地 } \\
\text { Grassland with low coverage }\end{array}$ & 20.42 & $0.41 \%$ \\
\hline \multirow{4}{*}{$\begin{array}{l}\text { 未利用地 } \\
\text { Unutilized lands (2.74\%) }\end{array}$} & 沼泽地 Marshes & 11.78 & $0.23 \%$ \\
\hline & 裸土地 Bare land & 94.70 & $1.88 \%$ \\
\hline & 沙地 Sand land & 6.69 & $0.13 \%$ \\
\hline & 裸岩石质地 Bare rock & 25.13 & $0.50 \%$ \\
\hline 合计 Total & & $5,041.30$ & $100.00 \%$ \\
\hline
\end{tabular}


黄越，顾炏芸，阳文锐，闻丞 (2021) 如何在北京充分实现受胁鸟类栖息地保护? 生物多样性, 29(3): 340350 .

http://www.biodiversity-science.net/CN/10.17520/biods.2020171

附录 3 eBird 受胁鸟类点位数据落位空间分布模型比例

Appendix 3 The percent of point data from eBird locating in the distributing model

\begin{tabular}{|c|c|c|c|c|c|c|}
\hline 物种 & 在鸟类栖 & 一级关键 & 二级关键 & 三级栖息 & 四级栖息地 & 不在鸟类栖息地范 \\
\hline \multirow[t]{5}{*}{ Species } & 息地范围 & 栖息地 & 栖息地 & 地 & The 4th & 围 \\
\hline & 内 & The 1st & The 2nd & The 3rd & Level & Percent outside the \\
\hline & Percent in & Level Key & Level Key & Level & Habitats & range of habitats \\
\hline & the range & Habitats & Habitats & Habitats & & \\
\hline & of habitats & & & & & \\
\hline 细纹苇莺 & $100.00 \%$ & $100.00 \%$ & $0.00 \%$ & $0.00 \%$ & $0.00 \%$ & $0.00 \%$ \\
\hline \multicolumn{7}{|c|}{ Acrocephalus } \\
\hline \multicolumn{7}{|c|}{ sorghophilus } \\
\hline 远东苇莺 & $100.00 \%$ & $0.00 \%$ & $20.00 \%$ & $0.00 \%$ & $80.00 \%$ & $0.00 \%$ \\
\hline \multicolumn{7}{|c|}{ Acrocephalus } \\
\hline \multicolumn{7}{|l|}{ tangorum } \\
\hline 鸿雁 & $80.28 \%$ & $40.85 \%$ & $5.63 \%$ & $7.04 \%$ & $26.76 \%$ & $19.72 \%$ \\
\hline \multicolumn{7}{|l|}{ Anser } \\
\hline \multicolumn{7}{|l|}{ cygnoides } \\
\hline 小白额雁 & $100.00 \%$ & $50.00 \%$ & $0.00 \%$ & $50.00 \%$ & $0.00 \%$ & $0.00 \%$ \\
\hline \multicolumn{7}{|l|}{ Anser } \\
\hline \multicolumn{7}{|l|}{ erythropus } \\
\hline 白肩雕 & $100.00 \%$ & $0.00 \%$ & $0.00 \%$ & $0.00 \%$ & $100.00 \%$ & $0.00 \%$ \\
\hline \multicolumn{7}{|c|}{ Aquila heliaca } \\
\hline 草原雕 & $100.00 \%$ & $100.00 \%$ & $0.00 \%$ & $0.00 \%$ & $0.00 \%$ & $0.00 \%$ \\
\hline \multicolumn{7}{|l|}{ Aquila } \\
\hline \multicolumn{7}{|l|}{ nipalensis } \\
\hline 青头潜鸭 & $94.44 \%$ & $44.44 \%$ & $11.11 \%$ & $5.56 \%$ & $33.33 \%$ & $5.56 \%$ \\
\hline \multicolumn{7}{|c|}{ Aythya baeri } \\
\hline 红头潜鸭 & $80.00 \%$ & $38.00 \%$ & $8.00 \%$ & $4.00 \%$ & $30.00 \%$ & $20.00 \%$ \\
\hline \multicolumn{7}{|c|}{ Aythya ferina } \\
\hline 东方白鹳 & $100.00 \%$ & $66.67 \%$ & $0.00 \%$ & $0.00 \%$ & $33.33 \%$ & $0.00 \%$ \\
\hline \multicolumn{7}{|l|}{ Ciconia } \\
\hline \multicolumn{7}{|l|}{ boyciana } \\
\hline 乌雕 & $87.50 \%$ & $12.50 \%$ & $25.00 \%$ & $0.00 \%$ & $50.00 \%$ & $12.50 \%$ \\
\hline \multicolumn{7}{|c|}{ Clanga clanga } \\
\hline 长尾鸭 & $100.00 \%$ & $66.67 \%$ & $0.00 \%$ & $0.00 \%$ & $33.33 \%$ & $0.00 \%$ \\
\hline \multicolumn{7}{|l|}{ Clangula } \\
\hline \multicolumn{7}{|l|}{ hyemalis } \\
\hline 褐马鸡 & $100.00 \%$ & $100.00 \%$ & $0.00 \%$ & $0.00 \%$ & $0.00 \%$ & $0.00 \%$ \\
\hline \multicolumn{7}{|c|}{ Crossoptilon } \\
\hline \multicolumn{7}{|c|}{ mantchuricum } \\
\hline 黄胸坐 & $75.00 \%$ & $32.14 \%$ & $7.14 \%$ & $0.00 \%$ & $35.71 \%$ & $25.00 \%$ \\
\hline
\end{tabular}


黄越，顾炏芸，阳文锐，闻丞 (2021) 如何在北京充分实现受胁鸟类栖息地保护? 生物多样性, 29(3): 340350 .

http://www.biodiversity-science.net/CN/10.17520/biods.2020171

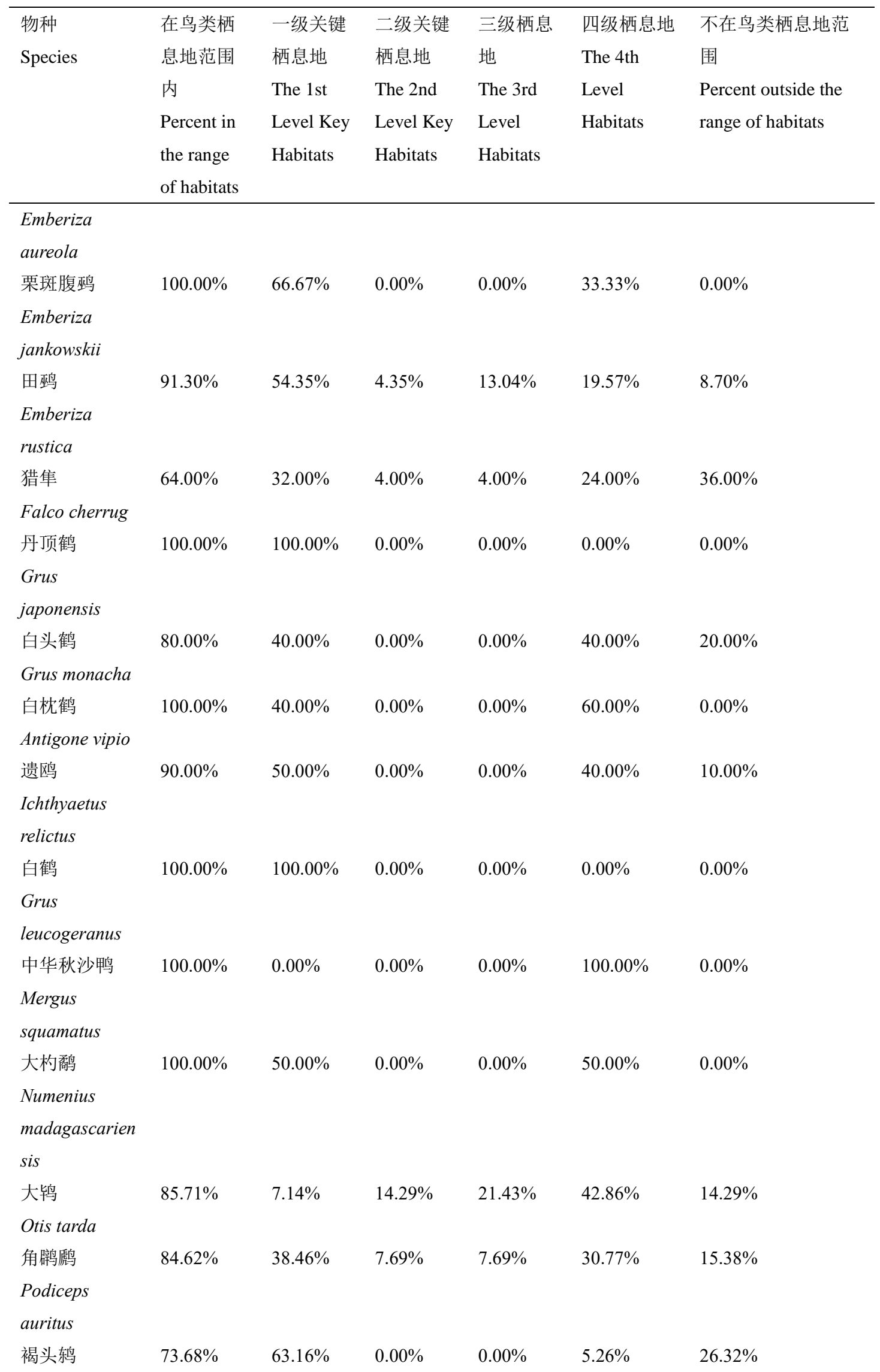


黄越，顾炏芸，阳文锐，闻丞 (2021) 如何在北京充分实现受胁鸟类栖息地保护? 生物多样性, 29(3): 340350 .

http://www.biodiversity-science.net/CN/10.17520/biods.2020171

\begin{tabular}{lllllll}
\hline 物种 & 在鸟类栖 & 一级关键 & 二级关键 & 三级栖息 & 四级栖息地 & 不在鸟类栖息地范 \\
Species & $\begin{array}{l}\text { 息地范围 } \\
\text { 内 栖息地 }\end{array}$ & 栖息地 & 地 & The 4th & 围 \\
& $\begin{array}{l}\text { The 1st } \\
\text { Percent in } \\
\text { the range } \\
\text { of habitats }\end{array}$ & The 2nd & The 3rd & Level & Percent outside the \\
& & & Level Key & Level & Habitats & range of habitats \\
& & & & & \\
\hline $\begin{array}{l}\text { Turdus feae } \\
\text { 总计 Total }\end{array}$ & $83.48 \%$ & $41.74 \%$ & $6.09 \%$ & $5.80 \%$ & $29.57 \%$ & $16.52 \%$ \\
\hline
\end{tabular}

